\title{
ЭМОЦИЯ «РАДОСТЬ» В ПУБЛИЦИСТИЧЕСКОМ ТЕКСТЕ (НА ПРИМЕРЕ НЕМЕЦКИХ ОНЛАЙН-СМИ)
}

\section{EMOTION "JOY" IN A PUBLIC TEXT (BASED ON THE GERMAN ONLINE MEDIA)}

M. Rusyaeva

N. Baranova

Summary: The article presents an analysis of one of the basic emotions - the emotions of joy- in the discourse of the modern German-speaking online media. The main ways of representation of the joy in the German publicistic text are considered in the article with the search and the analysis of the most common means of its language representation. In particular, the main way of linguistic representation of this emotion appears lexical item «sich freuen». In this case, the main text-building model of the transfer of emotion is the introduction of direct speech in the text. Celebrities most often act as a translator of emotions. The main emotions acting as a correlate of joy are "wonder", "contentment", "pacification", "anticipation", "dreaminess", "inspiration». The high intensity of emotions is often emphasized.

Keywords: basic emotions, joy, described emotion, invoked emotion, emotiveness, journalistic text.
Русяева Мария Михайловна

К.филол.н., дочент, Всероссийский государственный университет юстиции Средне-Волжский институт

(Саранск)

marijaru@mail.ru

Баранова Наталья Александровна

К.филол.н., доцент, Северный (Арктический) федеральный университет имени М.В. Ломоносова (Архангельск)

n.baranova@narfu.ru

Аннотация: В статье представлен анализ одной из базовых эмоций - эмоции «радость» - В дискурсе немецкоязычных онлайн - СМИ. В ней рассматриваются основные способы её выражения в публицистическом тексте, приводятся примеры языковых средств, используемых для репрезентации данной эмоции из современных немецкоязычных онлайн-источников. В частности, основным вербальным способом её выражения является глагол «sich freuen», а также производные от него. При этом основной текстопостроительной моделью передачи эмоции является введение прямой речи, через прямое цитирование или конструкции передачи «косвенной» речи. В роли транслятора эмоций наиболее часто выступают знаменитости. В качестве основных эмоций, выступающих коррелятом радости, в текстах СМИ встречаются «удивление», «удовлетворение», «умиротворение», «предвкушение», «мечтательность», «вдохновение». Нередко подчеркивается высокая интенсивность эмоции.

Ключевые слова: базовые эмоции, радость, описываемая эмоция, возбуждаемая эмоция, эмотивность, публицистический текст.
B современном мире наблюдаются изменения во всех сферах человеческой жизни, переход к цифровизации социального взаимодействия, уход в виртуальность «живого» общения, развитие информационного общества, попытки создать искусственный интеллект. Вышеперечисленные изменения породили ряд проблем, связанных с неумением и нежеланием людей общаться, что некоторые ученые связывают с недостаточным развитием, в частности, у молодых людей так называемого «эмоционального интеллекта»[1]. Параллельно с этим мы можем наблюдать повышения уровня «эмоциональности» в медиадискурсе. Это связано, прежде всего, с усилением прагматической функции публицистического текста, а именно возможностью влиять на общественное мнение. Большое внимание при этом уделяется приёмам, направленным на психологические реакции индивидов. Как известно, самым проверенным и безошибочным методом воздействия на человеческое сознание продолжает оставаться обращение к эмоциям и чувствам реципиента [6, с. 32].

СМИ влияют на настроения аудитории, порождая не только личные, но также политически и общественно значимые эмоции и чувства: скептицизм, цинизм, апатию, отчужденность, страх, покорность или же, наоборот, интерес, доверие, согласие, воодушевление, оптимизм, энтузиазм и т.д. При этом отсутствие «эмоционального интеллекта» делает человека мишенью для всякого рода манипуляций. Таким образом, актуальность данного исследования определяется, с одной стороны, необходимостью тщательного изучения эмоционального потенциала публицистического текста как субъекта влияния на общественное мнение. С другой стороны, современный медиатекст выступает в роли транслятора общечеловеческого опыта, в том числе и эмоционального [11, с. 242]. По мнению С.В. Ионовой, «индивидуальные эмоциональные переживания являются живым источником формирования национального и общечеловеческого опыта, устойчивость и узнаваемость эмоциональных смыслов, в свою очередь, обеспечивается за счет существования социального ядра эмоций - единых для всех представителей данной культуры образцов, стереотипов эмоциональных ситуаций и реакций на них [2, с. 5-6]. Следовательно, анализ эмоциональной составляющей 
публицистического текста будет способствовать выявлению специфических черт, присущих современной культуре.

На данный момент существует множество работ, посвященных изучению эмоций, о чем свидетельствуют многочисленные современные публикации на эту тему: С.В. Ионова [2,3,4], А.С. Кондина, Е.В. Пастухова [5], И.Н. Крутова [6], Т.А. Скотникова [7], Е.С. Смахтин, Д.Г. Васьбиева, О.А. Калугина [9], Е.В. Чупракова, Е.С. Попова [12], В.И. Шаховский $[13,14]$ и др. Однако, несмотря на пристальное внимание лингвистов к проблеме эмотивности текста, она все же остается до сегодняшнего дня одной из наиболее "размытых" областей исследования, которая и по сей день распределяется между стилистикой, семантикой и прагматикой речи [8, 10, с. 222]. Действительно, можно констатировать, что многие вопросы остаются открытыми, а понятийный аппарат лингвистики эмоций до сих пор не сформирован.

Применительно к языку принято употреблять термин «эмотивность», тогда как «эмоциональность» принято относить к области психологии. Наиболее точное определение «эмотивности» дано профессором В.И. Шаховским, который понимал под ним «имманентно присущее языку семантическое свойство выражать системой своих средств эмоциональность как факт психики, отраженные в семантике языковых единиц социальные и индивидуальные эмоции» [13, с. 24]. Вслед за С.В. Ионовой мы считаем, что «эмотивность» слишком широкое понятие, чтобы ограничиваться лишь лексическим и синтаксическим уровнем языка [3, с. 126], поскольку требуется учёт экстралингвистических факторов, лингвокультурологических аспектов, а также применение методов когнитивного анализа текста. В данной статье речь пойдет об эмотивности публицистического текста.

Говоря об «эмотивности» на текстовом уровне, следует разграничить такие понятия как «описываемая эмоция» (described emotion) и «возбуждаемая эмоция» (invoked emotion) [27]. Как уже было сказано выше, поскольку данное исследование не ограничивается лексико-семантическим уровнем, то нас интересуют не столько средства экспрессии, сколько то, как описываются сами эмоции в тексте, в каких ситуациях, кем продуцируются, для каких целей. В качестве объекта для анализа мы решили ограничиться базовыми эмоциями

На данный момент в современной психологической науке нет единой точки зрения относительно того, какие эмоции стоит относить к базовым. В результате разные авторы включают в перечни базовых эмоций разное их количество и зачастую - такие состояния, которые другие теоретики вообще не рассматривают как эмоции [7, с. 44]. Однако, из всей эмоциональной палитры можно выделить лишь несколько таких, которые присутствуют почти во всех основных перечнях базовых эмоций - радость, гнев, печаль и страх [7, с. 46]. В данной статье речь пойдет об одной из них, а именно о «радости».

Наиболее часто в публицистических текстах для выражения радости используется лексема «Freude - радость» или «sich freuen» - «радоваться». Что касается тематики публикаций, в которых данная эмоция упоминается, то, её условно можно поделить на следующие группы: радость от снятия карантинных ограничений, маленькие радости в условиях карантина, не связанные с пандемией темы - радости в спорте, частные радости известных людей.

Начало исследования было положено в феврале, когда тема пандемии не была столь актуальна. В то время эмоция «радость» появлялась в СМИ преимущественно в связи со спортивными событиями. Например: «Der 23-Jährigen genügte beim Finale am Königssee ein zweiter Platz hinter Teamkollegin und Überraschungssiegerin Anna Berreiter (Berchtesgaden). «lch kann es noch gar nicht fassen. Ich freue mich riesig», sagte Taubitz»[18]. В данном примере эмоция радости передается с помощью лексемы «sich freuen» в 1 лице ед. ч. - «lch freue mich riesig». Автор статьи использует включение в текст прямой речи, таким образом, персонализируя эмоцию. Нужно отметить, что данный прием довольно распространен. Это связано с антропоцентричностью эмоциональной сферы, ее субъективном характером. В связке с глаголом используется прилагательное «riesig», придающее крайнюю степень интенсивности эмоциональному переживанию. Еще один пример свидетельствует о распространенности эмоционального компонента именно среди публицистических текстов спортивной тематики: «Eine 16.8 auf dem C3 fühlt sich besonders und schnell an», sagt er. «Wir sind positiv geschockt, wie schnell wir sind. Ich freue mich darauf, das auf allen Strecken zu spüren. Das zaubert ein Lächeln auf mein Gesicht»[15] Здесь опять мы видим прямую речь и крайнюю степень интенсивности эмоционального переживания радости, выраженную с помощью словосочетания «positiv geschockt». Интересна в данном примере и отсылка к описанию невербального выражения эмоции радости - «Das zaubert ein Lächeln auf mein Gesicht». В связке позитивного радостного эмоционального фона данной статьи идут также такие слова маркеры как «ӓußerst zufrieden», «ein Lächeln im Gesicht», «glücklich», «Zuversicht» - «McLaren ist mit seinen Testfahrten äußerst zufrieden, Carlos Sainz hat ein Lächeln im Gesicht: Reichen die Fortschritte im Team wieder zu Rang vier? Bei McLaren herrscht nach den Formel-1-Testfahrten in Barcelona große Zuversicht. «Wir sind sehr glücklich, wie der Test für uns lief», sagt Teamchef Andreas Seidl»[15].

Следует подчеркнуть, что довольно часто в текстах подчеркивается высокая степень интенсивности эмоции радости. В основном это выражается при помощи 
сказуемого с соответствующим прилагательным в роли обстоятельства действия с яркой эмоциональной коннотацией: «Auf die ELMS und die 24 Stunden von Le Mans freue ich mich wahnsinnig. Le Mans ist der Hammer»[21], "lch freue mich riesig. Das ist wieder eine Riesenchance», sagte der 24-Jährige den Eishockey News»[19], «Das ist wunderschön. Ich freue mich riesig, die Kugel gleich in der Hand zu halten»[24]. Таким образом, эмоция «радости» в публицистических текстах спортивной тематики, подаётся в субъектной форме, персонифицировано, а именно принадлежит конкретным людям. Имеется указание на высокую степень её интенсивности. Поводом для радости служат спортивные достижения, надежды на будущие победы в складывающихся на данный момент удачных обстоятельствах.

Однако, эмоция радости продуцируется не только спортсменами. В публицистических текстах в качестве субъекта, чьи эмоции передаются, могут выступать и политики, и звезды шоу-бизнеса, и простые обыватели. Например: «Der US-Botschafter in Deutschland, Richard Grenell, wird der geschäftsführende Geheimdienstkoordinator im Weißen Haus. Das teilte USPräsident Donald Trump am Mittwochabend (Ortszeit) über Twitter mit. «Rick hat unser Land äußerst gut repräsentiert, und ich freue mich darauf, mit ihm zu arbeiten», schrieb Trump dazu»[17]. Стоит отметить, что американский президент довольно часто цитируется, при этом в его высказываниях много эмотивных лексем, нередко передающих радость: «lch freue mich darauf, mit dem indischen Volk zusammen zu sein», sagte Trump am Sonntag vor seiner Abreise in Washington»[25], «Der US-Präsident schrieb am Samstagabend (Ortszeit Washington) auf Twitter: «lch für meinen Teil freue mich, dass er wieder da ist und es ihm gut geht!» Trump setzt auf sein gutes Verhältnis zu Kim, um die derzeit stockenden Verhandlungen über Nordkoreas Atomwaffenprogramm wieder fortsetzen zu können [23]. Как мы видим из данных примеров, эмоция радости, также представлена глаголом sich freuen и передана от первого лица единственного числа, однако, по большей части цитируется твиттер американского президента, а не устная речь.

В речи немецких политиков также имеется эмоциональный компонент. Например, приводится высказывание Ulrike Liedtke: «Landtagspräsidentin Ulrike Liedtke sagte, sie freue sich, dass alle Abgeordneten dauerhaft vollzählig im Plenarsaal sitzen könnten» [22]. Как мы видим, в данном примере используется косвенная речь и глагол «sich freuen» в форме конъюнктива. «Die täglichen Neuinfektionen lägen bundesweit zum Teil nur noch im dreistelligen Bereich, sagte Merkel. Die Zahlen seien „sehr erfreulich"»- опять же встречаем форму конъюнктива, однако, эмоция обезличена.

Следует подчеркнуть, что когда речь идет об опи- сываемых эмоциях, основным способом введения их в публицистический текст, как уже было сказано выше, является прямая или косвенная речь, а также цитирование твиттера или других социальных сетей. Например: «lch freue mich ja, dass sich die CSU und Erwin Schneider vom echten Kenner-Könner-Kämpfer in ihrem Landratswahlkampf inspirieren lässt! Diesen Satz hat Dr. Wolfgang Heubisch (FDP), Landtagsvizepräsident und ehemaliger Wissenschaftsminister, auf seiner FacebookSeite gepostet»[22].

Звезды шоу-бизнеса также выражают свои эмоции на страницах газет. Так, например, немецкая певица Лена Мейер, вспоминая свою победу на Евровидении, говорит: «Sie könne «bis heute nicht richtig begreifen, was mir da passiert ist», schildert sie ihre Erfahrungen bei ESC in Oslo vor zehn Jahren. «lch fühle mich überfordert, immer noch. Es ist natürlich cool und toll, ich freue mich darüber, und ich bin dankbar. Aber manchmal sehe ich diese Bilder und denke: Das kann nicht ich gewesen sein. Es fühlt sich an wie ein anderes Leben.»[20] В данном примере мы находим много различных эмоциональных маркеров: «überfordert», «cool und toll», «dankbar». Интересен тот факт, что все они связаны с эмоцией «радость». В смысловом плане также примешивается чувство «удивления» - «bis heute nicht richtig begreifen, was mir da passiert ist» / «Das kann nicht ich gewesen sein. Es fühlt sich an wie ein anderes Leben». Снова встречаем прямую речь, персонифицированную передачу - выражение эмоций происходит в первом лице, единственного числа, конъюнктив.

Однако, в текстах СМИ описываются не только эмоции знаменитостей, хотя в количественном соотношении их всё-таки и больше, но и эмоции обывателей. Так, например, в статье газеты Reihnische Post описываются эмоции 8-летней девочки, празднующей лишь второй в жизни свое день рождение, поскольку он у неё приходится на 29 февраля: Am Tag selbst bekommt Alva Besuch von ihrem Uropa. Darauf freue sie sich besonders. „Die Familie hebt mich immer mit einem Stuhl hoch. Ich freue mich auf die Geschenke und den Kuchen", sagt Alva [16]. Опять встречаем форму конъюнктива и прямую речь от первого лица. Героиня публикации радуется, что в гостях был дедушка, подаркам и пирогам.

Пандемия внесла свои коррективы, в том числе и в темы публикаций СМИ. И на их страницах появилось больше статей о таких «простых» радостях, как в вышеприведенном примере.

Например, в газете «Neue Zuercher Zeitung» описываются «маленькие» радости карантинной жизни (12): «Vor allem auch der Stuhl, auf dem ich sitze. Ein Tessiner Stuhl mit einer Sitzfläche aus geflochtenem Stroh, und allein schon, dass er aus Kastanienholz gefertigt sein soll, lässt mich zwischenhinein von engen Tälern, kleinen Dörfern 
und Häusern mit steinernen Dächern träumen. Und auch wenn das etwas eigenartig klingt: Ich freue mich jeden Morgen auf diesen Stuhl. Wenn ich auf ihm sitze, glaube ich etwas von der Rauheit des Tessins zu spüren. Ich denke an Küchen mit russgeschwärzten Kaminen und stelle mir vor, wie es wäre, Polenta zu kochen oder Marroni zu rösten, statt Artikel zu redigieren und Mails zu schreiben. Ich glaube, weder Jack Kerouac noch Charles Bukowski waren je im Tessin. Aber an meinem Stuhl hätten sie ihre Freude gehabt»[26]. В данном примере объектом радости является стул, но стул не сам по себе, как красивый предмет мебели, а как источник для вдохновения, поэтому в качестве, того, кто, по мнению автора, мог бы разделить с ней эту радость, называются писатели Джек Керуак и Чарльз Буковски. Основой для вдохновения служит то место, где был произведен данный стул, а именно местечко Тессин в итальянской части швейцарских Альп. Перед нами предстает целый ассоциативный ряд, порожденный его происхождением - engen Tälern, kleinen Dörfern und Häusern mit steinernen Dächern, Küchen mit russgeschwärzten Kaminen, Polenta, Marroni... И во всем этом многообразии образов читается умиротворение тихой жизни. Таким образом, эмоция «радость» связывается с чувством покоя от простой «сельской» «уютной» «домашней» жизни в единении с природой. В языковом плане интересен прием противопоставления: «Polenta zu kochen oder Marroni zu rösten, statt Artikel zu redigieren und Mails zu schreiben». Городская суета противопоставляется сельскому покою. Также используется конъюнктив, но в данном случае не для передачи прямой речи, а для выражения нереального, но желаемого: «Ich glaube, weder Jack Kerouac noch Charles Bukowski waren je im Tessin. Aber an meinem Stuhl hätten sie ihre Freude gehabt.». Однако, учитывая то, каких именно писателей приводит автор, понимаешь, что кроме «простой» жизни без суеты, к эмоции «радость» привносится еще и дух свободы.

Таким образом, можно прийти к следующим выводам. В публицистических текстах эмоция «радость» встречается довольно часто. Основным вербальным способом её выражения является глагол «sich freuen», а также производные от него. При этом в тексте почти всегда есть агенс. В качестве основного актора выступает 1 лицо, единственное число. Основной текстопостроительной моделью передачи эмоции является введение прямой речи, через прямое цитирование или конструкции передачи «косвенной» речи. В роли транслятора эмоций выступают знаменитости: спортсмены, политики, представители шоу-бизнеса. Объектом радости становятся какие-то знаковые события жизни в основном связанные с карьерой или профессиональной деятельностью. Объектом радости обывателей являются «обычные» вещи. В качестве основных эмоций, выступающих коррелятом радости, в текстах СМИ встречаются «удивление», «удовлетворение», «умиротворение», «предвкушение», «мечтательность», «вдохновение». Нередко подчеркивается высокая интенсивность эмоции.

\section{ЛИТЕРАТУРА}

1. Бочкова М.Н., Мешкова Н.В. Эмоциональный интеллект и социальное взаимодействие: зарубежные исследования [Электронный ресурс] // Современная зарубежная психология. - 2018. Том 7. № 2. С. 49-59. URL: https://psyfactor.org/lib/emotional-intellect-2.htm (дата обращения: 14.03.2020).

2. Ионова С.В. Актуальные проблемы лингвистики текста // Актуальные проблемы филологии и педагогической лингвистики. Вып. 11. Сб. науч. тр. Владикавказ, 2009. - С. 122-127.

3. Ионова С.В. Лингвистика эмоций - наука будущего [Электронный ресурс] // Известия ВГПУ. 2019. №1 (134). URL: https://cyberleninka.ru/article/n/ lingvistika-emotsiy-nauka-buduschego (дата обращения: 14.03.2020).

4. Ионова С.В. Эмотивность текста как лингвистическая проблема. Автореф. дис. ....канд.филол.наук. Волгоград. 1998. 14 с.

5. Кондина А.С., Пастухова Е.В. Проявление эмоционального интеллекта как существенный признак нарративизации вторичной языковой личности [Электронный ресурс] // Верхневолжский филологический вестник. 2019. №2. URL: https://cyberleninka.ru/article/n/proyavlenie-emotsionalnogo-intellekta-kaksuschestvennyy-priznak-narrativizatsii-vtorichnoy-yazykovoy-lichnosti (дата обращения: 14.03.2020).

6. Крутова И.Н. Заголовок публицистического текста как формирующий регулянт эмотивно-дискурсивного пространства // Гуманитарные исследования. 2018. № 4(68). С. 32-36.

7. Овсянникова В.В. К вопросу о классификации эмоций: категориальный и многомерный подходы [Электронный ресурс] // Финансовая аналитика: проблемы и решения. 2013. №37. URL: https://cyberleninka.ru/article/n/k-voprosu-0-klassifikatsii-emotsiy-kategorialnyy-i-mnogomernyy-podhody (дата обращения: 09.03.2020).

8. Скотникова Т.А. Фразеологические обороты как средство реализации эмотивности немецкоязычных газетно-публицистических текстов на правовую тематику // Филологические науки. Вопросы теории и практики - Тамбов: Грамота, 2020. Том 13. Выпуск 1. С. 222-225.

9. Смахтин Е.С., Васьбиева Д.Г., Калугина О.А. Особенности вербализации эмоций в публицистических текстах экономической направленности [Электронный ресурс] // Филологические науки. Вопросы теории и практики. 2018. №4-2 (82). URL: https://cyberleninka.ru/article/n/osobennosti-verbalizatsiiemotsiy-v-publitsisticheskih-tekstah-ekonomicheskoy-napravlennosti (дата обращения: 14.03.2020).

10. Телия В.Н. Человеческий фактор в языке: языковые механизмы экспрессивности / Ин-т языкознания. М.: Наука, 1991. 214 с.

11. Цыбульская М.П. Эмотивность в современных медиатекстах (гендерный аспект) [Электронный ресурс] // Роль женщины в развитии современной науки 
и образования: сборник материалов Международной научно-практической конференции, 17-18 мая 2016 г., Минск / БГУ; редкол.: И.В. Казакова, А.В. Бутина, И.В. Олюнина. - Минск: БГУ, 2016. С. 241-244. URL: http://elib.bsu.by/handle/123456789/195239 (дата обращения: 14.03.2020).

12. Чупракова Е.В., Попович Е.С. Особенности репрезентации категории эмотивности в английском публицистическом тексте [Электронный ресурс] // 0бщество и право. 2014. №2 (48). URL: https://cyberleninka.ru/article/n/osobennosti-reprezentatsii-kategorii-emotivnosti-v-angliyskom-publitsisticheskom-tekste (дата обращения: 14.03.2020).

13. Шаховский В.И. Лингвистическая теория эмоций: монография. М.: Гнозис, 2008. 416 с.

14. Шаховский, В.И. Эмоции как объект исследования в лингвистик [Электронный ресурс] // Вопросы психолингвистики. - 2009. - №9. URL: https:// cyberleninka.ru/article/n/emotsii-kak-obekt-issledovaniya-v-lingvistike (дата обращения: 14.03.2020).

15. «Sind positiv geschockt»: McLaren auch ohne Topzeiten Spitze des Mittelfeldes? Motorsport. [Электронный ресурc]. - URL: https://www.motorsport-total.com/ formel-1/news/sind-positiv-geschockt-mclaren-auch-ohne-topzeiten-spitze-des-mittelfeldes-20022903 (дата обращения: 14.03.2020).

16. Am Schalttag geboren. Achtjährige feiert zweiten Geburtstag. Reihnische Post. [Электронный ресурс]. - URL: https://rp-online.de/nrw/staedte/geldern/alvaverheyen-aus-geldern-wurde-im-schaltjahr-geboren_aid-49053691(дата обращения: 14.03.2020).

17. Donald Trump: Richard Grenell wird neuer Geheimdienstkoordinator von US-Präsident. Spiegel. [Электронный ресурc]. - URL: https://www.spiegel.de/politik/ ausland/richard-grenell-bisheriger-us-botschafter-in-berlin-wird-geheimdienstkoordinator-a-0d16dd38-4c13-4603-a1fb-efeda1e4е014 (дата 0бращения: 14.03.2020).

18. Doppelsieg für deutsche Rodler: Taubitz setzt Serie fort. IDOWA. [Электронный ресурс]. - URL: https://www.idowa.de/inhalt.weltcup-am-koenigsseedoppelsieg-fuer-deutsche-rodler-taubitz-setzt-serie-fort.d2779bb0-95f7-4b05-9599-97bdefdd3bd5.html (дата обращения: 14.03.2020).

19. Kahun nach Buffalo-Wechsel: «Das ist wieder eine Riesenchance». Yahoo Nachrichten. [Электронный ресурс]. - URL: https://de.sports.yahoo.com/news/kahunbuffalo-wechsel-riesenchance-053100958.html (дата обращения: 14.03.2020).

20. Lena Meyer-Landrut über Raab und den ESC: «lch fühle mich überfordert, immer noch». YahooNachrichten. [Электронный pecypc]. - URL: https://de.nachrichten. yahoo.com/lena-meyer-landrut-\%C3\%BC-raab-104817103.html 77734 (дата обращения: 14.03.2020).

21. Pionierin Flörsch: Das ist mein Formel-1-Plan. Yahoo Nachrichten. [Электронный ресурс]. - URL: https://de.sports.yahoo.com/news/pionierin-fl\%C3\%B6rschformel-1-plan-180900071.html (дата обращения: 14.03.2020).

22. Politik hinter Plexiglas im Brandenburger Landtag. Berliner Zeitung. [Электронный ресурс]. - URL: https://www.berliner-zeitung.de/mensch-metropole/merkelkeinerlei-erhoehungen-von-abgaben-und-steuern-geplant-li.77734 (дата обращения: 14.03.2020).

23. Rückkehr von Kim Jong Un Donald Trump: «Freue mich, dass er wieder da ist». RTL [Электронный ресурc]. - URL: https://www.rtl.de/cms/donald-trump-freuemich-dass-er-wieder-da-ist-4534505.html (дата обращения: 14.03.2020).

24. aubitz hat Druck ausgehalten. Yahoo Nachrichten. [Электронный ресурc]. - URL: https://de.sports.yahoo.com/news/deutsche-doppelsitzer-sicherngesamtweltcup-122019087.html (дата обращения: 14.03.2020).

25. Trump rechnet bei Staatsbesuch in Indien mit «Millionen» jubelnder Menschen. YahooNachrichten. [Электронный ресурс]. - URL: https://de.nachrichten.yahoo. com/trump-rechnet-staatsbesuch-indien-millionen-jubelnder-menschen-213856110.html (дата обращения: 14.03.2020).

26. Der Coronavirus-Alltag bringt uns auf neue Gedanken. Neue Zürcher Zeitung. [Электронный ресурс]. - URL: https://www.nzz.ch/feuilleton/der-coronovirusalltag-bringt-uns-auf-neue-gedanken-Id.1547617 (дата обращения: 14.03.2020)

27. Ungerer F. Emotions and emotional language in English and German news stories / F. Ungerer // The language of Emotions. - 1997. - P. 307-328.

(с Русяева Мария Михайловна (marijaru@mail.ru ), Баранова Наталья Александровна (n.baranova@narfu.ru) . 